Volume 9. No. 8, August 2021

International Journal of Emerging Trends in Engineering Research

Available Online at http://www.warse.org/IJETER/static/pdf/file/ijeter24982021.pdf https://doi.org/10.30534/ijeter/2021/24982021

\title{
Low Frequency AC Transmission for Offshore Wind Power
}

\section{${ }^{1}$ K. NAGAMANI, ${ }^{2}$ PENAGANTI MADHU SUDHAN RAO,${ }^{3}$ VETURU JAYANTH, ${ }^{4}$ RONGALI SATHYA RAGHAV, ${ }^{5}$ MOGANTI SAI KIRAN}

\author{
${ }^{1}$ ASSISTANT PROFESSOR, Department of EEE, Lendi Institute of Engineering and Technology, INDIA, \\ nagamani.kalyampudi@gmail.com \\ ${ }^{2}$ STUDENT, Department of EEE, Lendi Institute of engineering and technology, INDIA, \\ Penagantimadhu99@gmail.com \\ ${ }^{3}$ STUDENT, Department of EEE, Lendi Institute of engineering and technology, INDIA, jayanthveturu@ gmail.com \\ ${ }^{4}$ STUDENT, Department of EEE, Lendi Institute of engineering and technology, INDIA, \\ rongalisathyaraghav@gmail.com \\ ${ }^{5}$ STUDENT, Department of EEE, Lendi Institute of engineering and technology, INDIA, Avyakthpatnaik@gmail.com
}

\begin{abstract}
This paper presents a low frequency ac (LFAC) transmission system for offshore wind power. The LFAC system is interfaced with the main power grid with a cycloconverter. The wind power plant collection system is dc based, and connects to the LFAC transmission line with a 12-pulse thyristor converter. A method to design the system's components and controls is set forth. Simulation results are provided to illustrate the system's performance.
\end{abstract}

Key words : Power transmission, thyristor converters, underwater power cables, wind energy.

\section{INTRODUCTION}

OFFSHORE wind power plants are expected to represents significant component of the future electric generation portfolio due to greater space availability and better wind energy potential in offshore locations. The integration of offshore wind power plants with the main power grid is a subject of ongoing research. Presently, high-voltage ac (HVAC) and high voltage dc (HVDC) are wellestablished technologies for transmission.

HVAC transmission is advantageous because it is relatively straightforward to design the protection system and to change voltage levels using transformers. However, the high capacitance of submarine ac power cables leads to considerable charging current, which, in turn, reduces the active power transmission capacity and limits the transmission distance. HVAC is adopted for relatively short (up to 50-75 km) underwater transmission distances. In LFAC systems, an intermediate frequency level is used, which is created using a cycloconverter that lowers the grid frequency to smaller value, typically to one-third its value.
In general, the main advantage of the LFAC technology is the increase of power capacity and transmission distance for a given submarine cable compared to $50-\mathrm{Hz}$ or $60-\mathrm{Hz}$ HVAC.

This leads to substantial cost savings due to the reduction in cabling requirements (i.e., less lines in parallel for a desired power level) and the use of normal ac breakers for protection.

In this paper, a novel LFAC transmission topology is analyzed. The proposed system differs from previous work in that the wind turbines are assumed to be interconnected with a medium voltage (MV) dc grid, in contrast with current practice, where the use of MV ac collection grids is standard. DC collection is becoming a feasible alternative with the development of cost effective and reliable dc circuit breaker, and studies have shown that it might be advantageous with respect to ac collection in terms of efficiency and improved production costs.

The required dc voltage level can be built by using highpower dc-dc converters and/or by the series connection of wind turbines. For example, multi-MW permanentmagnet synchronous generators with fully rated power converters (Type-4 turbines) are commonly used in offshore wind plants. By eliminating grid-side inverters, a medium voltage dc collection system can be formed by interconnecting the rectified output of the generators. The main reason for using a dc collection system with LFAC transmission is that the wind turbines would not need to be redesigned to output low frequency ac power, which would lead to larger, heavier, and costlier magnetic components (e.g.,step-up transformers and generators). The design of the dc collection system is outside the scope of this paper. At the sending end of the proposed LFAC system, a dc/ac 12-pulse thyristor-based inverter is used to generate lowfrequency (20- or $162 / 3-\mathrm{Hz}$ ) ac power, as shown in Fig. 


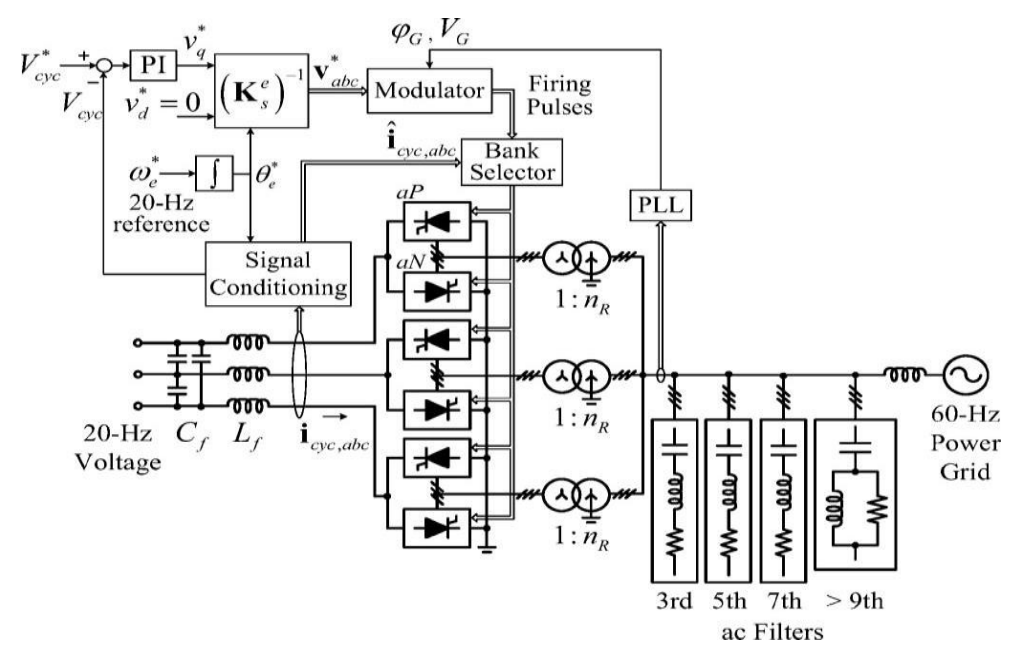

Fig. 3. shows Receiving-end cycloconverter control

\section{SYSTEM DESIGN}

\section{MAIN POWER COMPONENTS}

The main power components are selected based on a steady state analysis of the LFAC transmission system shown in Fig. 1, under the following assumptions:

- Only fundamental components of voltages and currents are considered. The receiving end is modeled as a $20 \mathrm{~Hz}$ voltage source of nominal magnitude.

- The power losses of the reactor, thyristors, filters, and transformers are ignored.

- The resistances and leakage inductances of transformers are neglected.

- The ac filters are represented by an equivalent capacitance corresponding to the fundamental frequency.

- The design is based on rated operating conditions (i.e., maximum power output).

At the steady state, the average value of the dc current is equal to, so the power delivered from the wind turbines.

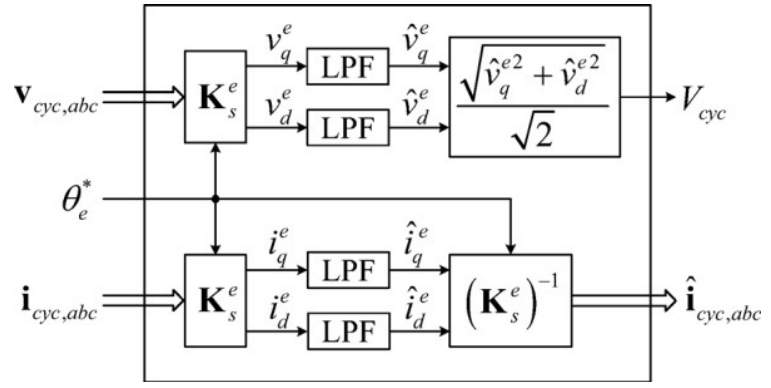

Fig. 4. shows Details of the signal conditionimg block. (LPF first-order low-pass filters, with time constants equal to 0.05 $\mathrm{s}$ and $0.01 \mathrm{~s}$ for the voltage and current, respectively.

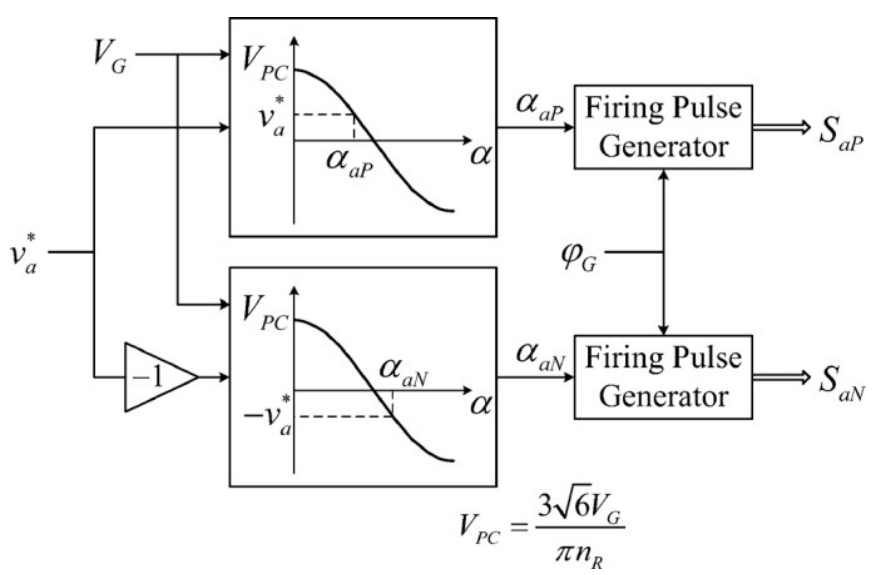

Fig. 5. shows Modulator for phase $\boldsymbol{C}$

\section{FILTER DESIGN}

At the sending end, the 12-pulse inverter produces harmonics of order $\quad 1,2, \ldots$ and can be represented as a source of harmonic currents (in Fig. 7). These current harmonics are filtered by two single-tuned filters for the 11th and 13th harmonic, and one damped filter for higher order harmonics ( $\geq 23 \mathrm{rd}$ ). Generally, the filter design is dependent on the reactive power supplied at fundamental frequency (also known as the filter size) and the required quality factor. The total reactive power requirement of these filters can be estimated. Here, it is assumed that the total reactive power requirement is divided equally among the three filters. The quality factor for each filtercan be determined using the method presented. A High-Quality Factor $(Q F=100)$ is used for the single tuned filters, and a Low-Quality Factor is used for the high pass damped filter. Finally, with the capacitance and quality factor known, the inductance and resistance of each filter can be determined. With such filter design, the 12-pulserelated current harmonics originating at the sending end are essentially absent from the transmission line.

At the receiving end, there are two groups of filters, namely,the ac filters at the $60 \mathrm{~Hz}$ side and the $L C$ filter at the $20 \mathrm{~Hz}$ side. At the $60 \mathrm{~Hz}$ side, if the cycloconverter generates exactly one-third of the grid frequency, and it can be shown [30, p. 360]that the line current has only odd harmonic components (3rd, 5th, 7th, etc). Subharmonic and inter harmonic components are not generated. Here, three single-tuned filters and one damped filter are used to prevent these harmonic currents from being injected into the $60 \mathrm{~Hz}$ power grid. These filters are designed with a procedure similar to that for the ac filters at the sending end. 
K. NAGAMANI, et al., International Journal of Emerging Trends in Engineering Research, 9(8), August 2021, 1179 - 1184

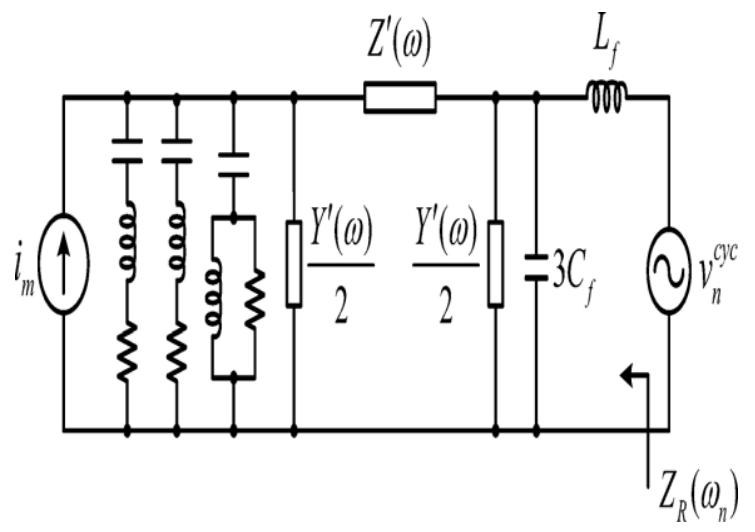

Fig. 6. Shows Equivalent circuit of the LFAC transmission system for harmonic analysis.

At the $20 \mathrm{~Hz}$ side, the line-to-neutral voltage has harmonics of order $3,5,7, \ldots$. Without subharmonic and inter harmonic components [30, p. 306]. However, the harmonic components of order equal to integer multiples of three are absent in the line-to-line voltage. Therefore, as seen from the $20 \mathrm{~Hz}$ side, the cycloconverter acts as a source of harmonic voltages of orders $n=6 k+1, k=1,2, \ldots($ $v_{n}^{2 \cdot 3 c}$ in Fig. 6).

The design of the $L C$ filter has two objectives:

1) to decrease the amplitudes of the voltage harmonics generated by the cycloconverter;

2) to increase the equivalent harmonic impedance magnitudes seen from the receiving end, indicated by $Z_{R}\left(\omega_{n}\right)$ in Fig. 6 .

The design procedure presented here takes into account the voltage harmonics of order 5, 7, 11, and 13. For cycloconverters, the amplitude of the voltage harmonics only depends on the voltage ratio and the fundamental power factor at the $20 \mathrm{~Hz}$ side, under the assumption of sinusoidal output current, which is sufficient for design purposes. Generally, the voltage harmonics tend to become worse with decreasing.

Fig. 8 illustrates the relationship between the per unit amplitudes of the voltage harmonics under consideration and the power factor angle $\phi$, computed based on formulas in [30, p. 303]. Apparently, for the 5th and 7th voltage harmonics, the amplitudes are symmetric with respect to $\phi$, and positive $\phi$ (i.e., reactive power consumption by the cycloconverter) can result in reduced amplitudes of the 11 th and $13^{\text {th }}$ harmonic currents. However, this value is unacceptably low, so selected (for operation at rated power).

After has been determined, it follows from (18) and (19) that there is a linear relation between $L_{f}$ and

$C_{f}$, as in $a L_{f}+b$, since $\tan (\phi) \quad Q_{\mathrm{cyc}}^{20} / P_{c y c \mathrm{c}}^{20}$

\section{SIMULATION RESULTS}

To demonstrate the validity of the proposed LFAC system, simulations have been carried out using MATLAB/Simulink and the Piecewise Linear Electrical Circuit Simulation (PLECS)

The wind power plant is rated at $180 \mathrm{MW}$, and the transmission distance is $160 \mathrm{~km}$. The system parametersare listed in Table I. The parameters of the PI controllers in Figs. 2 and 3 are listed in Table II. The transmission power cable is modeled by cascading 20 identical sections. The ABB 5STP $42 \mathrm{U} 6500$ and the ABB 5STP 08F6500 thyristors are selected to construct the sending end inverter and the receiving end cycloconverter, respectively. Multiple series connected 5 thyristors at the sending end and 30 thyristors at the receiving end are used such that the rated voltage of a switch is $150 \%$ of the rated blocking voltage.

Fig. 13 shows the steady state line-to-line voltage and current waveforms at the sending end, the receiving end, the $20 \mathrm{~Hz}$ side of the cycloconverter, and the $60 \mathrm{~Hz}$ power grid side under rated power conditions. The $20 \mathrm{~Hz}$ voltage generated from the cyclo- converter has significant harmonic distortion (THD is $14.8 \%$ ). Due to the $L C$ filter, the voltages at the receiving and sending ends have reduced THD values (3.9\% and $2.2 \%$, respectively).The measured fundamental power factor angle $\phi$ at the $20 \mathrm{~Hz}$.

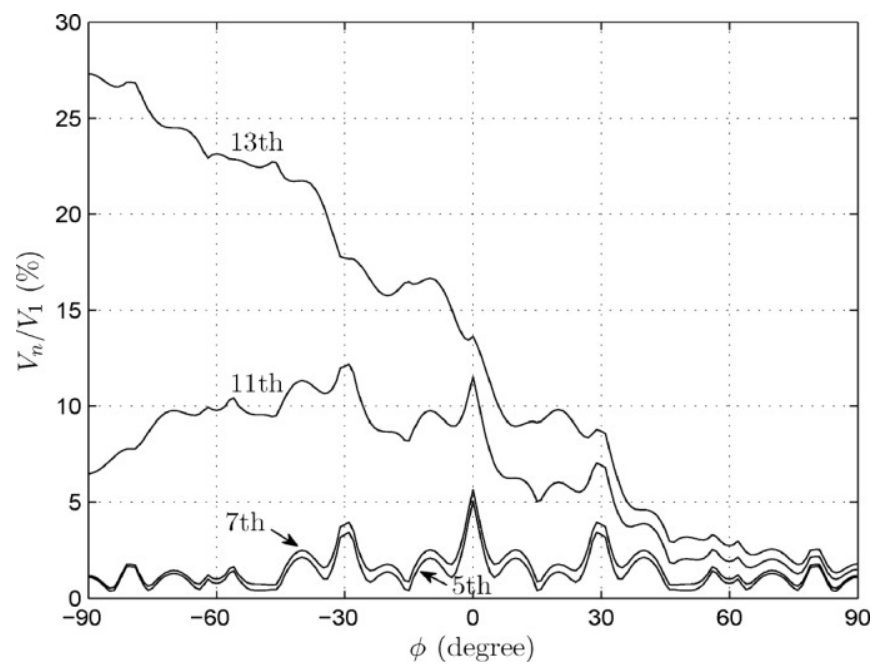

Fig. 7. Shows Harmonic voltage amplitudes generated by the cycloconverter at the $20-\mathrm{Hz}$ side. 
K. NAGAMANI, et al., International Journal of Emerging Trends in Engineering Research, 9(8), August 2021, 1179 - 1184

Table 1: LFAC SYSTEM SIMULATION PARAMETERS

\begin{tabular}{|c|c|c|c|}
\hline \multicolumn{4}{|c|}{ Sending End } \\
\hline \multicolumn{2}{|c|}{ dc Bus Capacitor } & \multicolumn{2}{|c|}{$C=1000 \mu \mathrm{F}$} \\
\hline \multicolumn{2}{|c|}{ Smoothing Inductor } & \multicolumn{2}{|c|}{$L=0.1 \mathrm{H}, R=1 \mathrm{~m} \Omega$} \\
\hline \multicolumn{4}{|c|}{ 20-Hz Phase-shift Transformer } \\
\hline Rated Power & 214 MVA & Voltage & $132 / 13.2 \mathrm{kV}$ \\
\hline $\begin{array}{c}\text { Winding } \\
\text { Resistance }\end{array}$ & 0.001 p.u. & $\begin{array}{l}\text { Leakage } \\
\text { Reactance }\end{array}$ & 0.05 p.u. \\
\hline $\begin{array}{l}\text { Magnetizing } \\
\text { Resistance }\end{array}$ & 1000 p.u. & $\begin{array}{l}\text { Magnetizing } \\
\text { Reactance }\end{array}$ & 200 p.u. \\
\hline \multicolumn{4}{|c|}{ ac Filters (115 MVAr, $132 \mathrm{kV}, 20 \mathrm{~Hz})$} \\
\hline & $\mathrm{R}(\Omega)$ & $\mathrm{L}(\mathrm{mH})$ & $\mathrm{C}(\mu \mathrm{F})$ \\
\hline 11 th & 0.41 & 29.7 & 17.6 \\
\hline 13 th & 0.35 & 21.3 & 17.6 \\
\hline$>23 \mathrm{rd}$ & 19.7 & 6.8 & 17.6 \\
\hline
\end{tabular}

Transmission Power Cable (132 kV)

\begin{tabular}{|c|c||c|c|}
\hline \hline Resistance & $17.6 \mathrm{~m} \Omega / \mathrm{km}$ & Inductance & $0.35 \mathrm{mH} / \mathrm{km}$ \\
\hline Capacitance & $0.25 \mu \mathrm{F} / \mathrm{km}$ & Rated Current & $825 \mathrm{~A}$ \\
\hline \hline
\end{tabular}

Receiving End

\begin{tabular}{|c|c|c|c|}
\hline \multicolumn{2}{|c|}{$L C$ Filter } & \multicolumn{2}{|c|}{$L_{f}=63 \mathrm{mH}, C_{f}=8.7 \mu \mathrm{F}$} \\
\hline \multicolumn{4}{|c|}{ Transformers } \\
\hline Rated Power & $100 \mathrm{MVA}$ & Voltage & $132 / 88 \mathrm{kV}$ \\
\hline $\begin{array}{c}\text { Winding } \\
\text { Resistance }\end{array}$ & 0.001 p.u. & $\begin{array}{l}\text { Leakage } \\
\text { Reactance }\end{array}$ & 0.05 p.u. \\
\hline $\begin{array}{l}\text { Magnetizing } \\
\text { Resistance }\end{array}$ & 1000 p.u. & $\begin{array}{l}\text { Magnetizing } \\
\text { Reactance }\end{array}$ & 200 p.u. \\
\hline \multicolumn{4}{|c|}{ ac Filters $(200 \mathrm{MVAr}, 132 \mathrm{kV}, 60 \mathrm{~Hz})$} \\
\hline & $\mathrm{R}(\Omega)$ & $\mathrm{L}(\mathrm{mH})$ & $\mathrm{C}(\mu \mathrm{F})$ \\
\hline $3 \mathrm{rd}$ & 1.16 & 102.7 & 7.6 \\
\hline 5 th & 0.70 & 37.0 & 7.6 \\
\hline 7 th & 0.50 & 18.9 & 7.6 \\
\hline$>9$ th & 38.7 & 11.4 & 7.6 \\
\hline
\end{tabular}

Table 2 : PARAMETERS OF PI CONTROLLERS WITH $H(s)=h(1+(1) /(\tau s)$

\begin{tabular}{|c||c|c|}
\hline & Sending end & Receiving end \\
\hline \hline$K$ & 1 & 0.125 \\
\hline$\tau$ & 0.1 & 0.05 \\
\hline
\end{tabular}
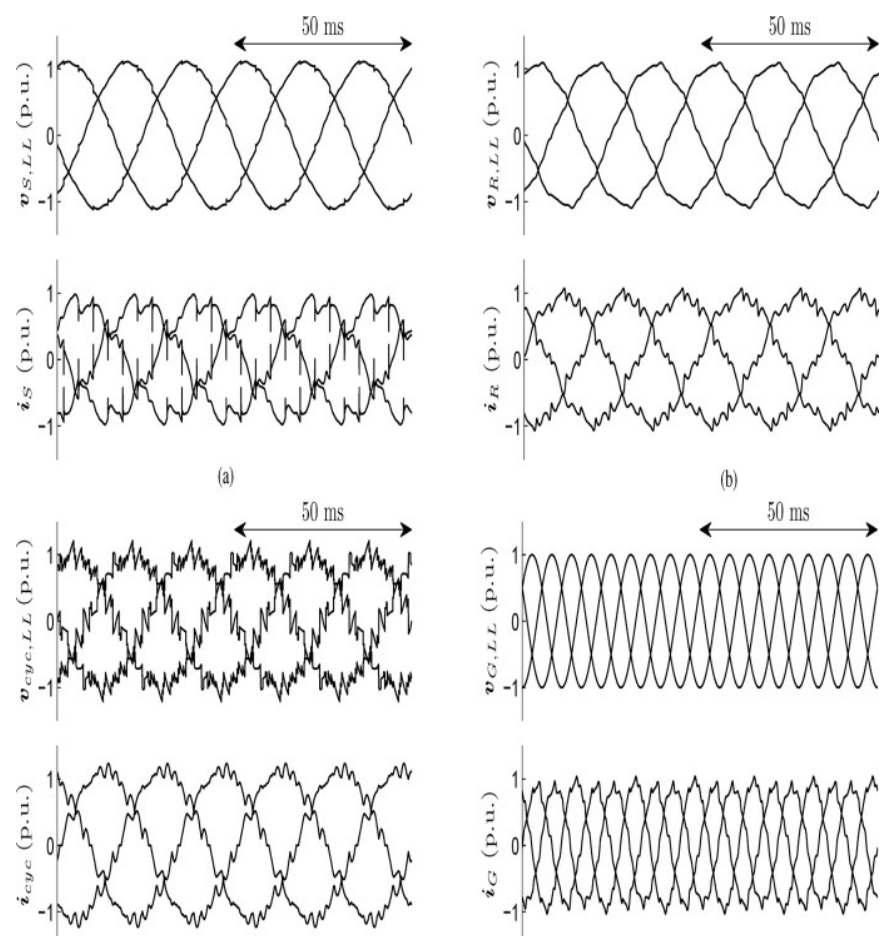

(c)

(d)

Fig. 8. shows Simulated voltage and current waveforms. (Please refer to Fig. 1 for voltage and current monitoring positions.) (a) Sending end. (b) Receiving end.

(c) Cycloconverter $20-\mathrm{Hz}$ side. (d) $60-\mathrm{Hz}$ power grid side.

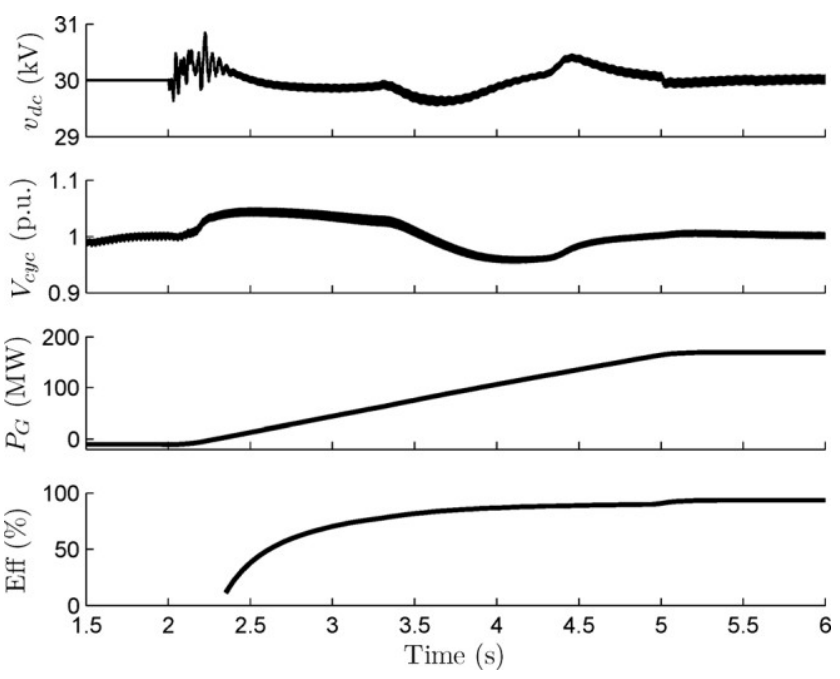

Fig. 9. shows Transient waveforms during a wind power ramp event. 
Fig. 9 depicts the results of a transient simulation where the power from the wind turbines $I^{\prime}{ }^{\prime}$ 'ramps from 0 to $180 \mathrm{MW}$, at a rate of $60 \mathrm{MW} / \mathrm{s}$ (perhaps unrealistically fast, but chosen to demonstrate that the system is stable even for this large transient). Shown are the transient responses of the dc bus voltage at the sending end, the magnitude of the fundamental component of the $20 \mathrm{~Hz}$ voltage generated by the cycloconverter, the active power injected into the $60 \mathrm{~Hz}$ power grid, and the transmission efficiency (which reaches a value of $93.3 \%$ at rated power).

\section{CONCLUSION}

A low frequency ac transmission system for offshore wind power has been proposed. A method to design the system's components and control strategies has been discussed. The use of a low frequency can improve the transmission capability of submarine power cables due to lower cable charging current. The proposed LFAC system appears to be a feasible solution for the integration of offshore wind power plants over long distances, and it might be a suitable alternative over HVDC systems in certain cases. Furthermore, it might be easier to establish an interconnected low frequency ac network to transmit bulk power from multiple plants. In order to make better informed decisions, it is necessary to perform a complete technical and economic comparison among HVAC, HVDC, and LFAC, evaluating factors, such as the transmission efficiency, investment and operating costs, and the performance under system transients.

\section{REFERENCES}

[1] N. B. Negra, J. Todorovic, and T. Ackermann, "Loss evaluation of HVAC and HVDC transmission solutions for large offshore wind farms," Elect. Power Syst. Res., vol. 76, no. 11, pp. 916-927, Jul. 2006.

[2] S. Bozhko, G. Asher, R. Li, J. Clare, and L. Yao, "Large offshore DFIG- based wind farm with line-commutated HVDC connection to the main grid: Engineering studies," IEEE Trans. Energy Convers., vol. 23, no. 1, pp. 119-127, Mar. 2008.

[3] O. Gomis-Bellmunt, J. Liang, J. Ekanayake, R. King, and N. Jenkins, "Topologies of multiterminal HVDC-VSC transmission for large off-shore wind farms," Elect. Power Syst. Res., vol. 81, no. 2, pp. 271-281, Feb. 2011.

[4] P. Bresesti, W. L. Kling, R. L. Hendriks, and R. Vailati, "HVDC connection of offshore wind farms to the transmission system," IEEETrans. Energy Convers., vol. 22, no. 1, pp. 37-43, Mar. 2007.

[5] S. V. Bozhko, R. Blasco-Giménez, R. Li, J. C. Clare, and G. M. Asher, "Control of offshore DFIG-based wind farm grid with linecommutated HVDC connection," IEEE Trans. Energy Convers., vol. 22, no. 1, pp.71-78, Mar. 2007.

[6] J. Arrillaga, High Voltage Direct Current Transmission, 2nd ed. London, U.K.: Institution of Electrical Engineers, 1998.
[7] N. Flourentzou, V. G. Agelidis, and G. D. Demetriades, "VSC-based HVDC power transmission systems: An overview," IEEE Trans. Power Electron., vol. 24, no. 3, pp.

592-602, Mar. 2009.

[8] T. Funaki and K. Matsuura, "Feasibility of the lower frequency AC transmission," in Proc. IEEE Power Eng. Soc. Winter Meeting, 2000, vol. 4, pp. 2693-2698.

[9] X. Wang, C. Cao, and Z. Zhou, "Experiment on fractional frequency transmission system," IEEE Trans. Power Syst., vol. 21, no. 1, pp. 372-377, Feb. 2006.

[10] N. Qin, S. You, Z. Xu, and V. Akhmatov, "Offshore wind farm connec- tion with low frequency ac transmission technology," presented at the IEEE Power Energy Soc. Gen. Meeting, Calgary, AB, Canada, 2009.

[11] Y. Cho, G. J. Cokkinides, and A. P. Meliopoulos, "Time domain sim-ulation of a three-phase cycloconverter for LFAC transmission sys- tems," presented at the IEEE Power Energy Soc. Transm. Distrib. Conf. Expo., Orlando, FL, May 2012. 